\title{
Persepsi mahasiswa terhadap skenario pembelajaran problem based learning
}

\author{
Eli Trisnowati, dan Riva Ismawati \\ Universitas Tidar \\ Jalan Kapten Suparman 39 Magelang 56II6 \\ Surat-e: elitrisnowati@untidar.ac.id
}

Model pembelajaran problem based learning merupakan salah satu model pembelajaran yang digunakan dalam pembelajaran abad 2I. Keterlaksanaan proses pembelajaran dapat dilihat dari kesiapan guru dan peserta didik. Kesiapan peserta didik dapat dilihat dari persepsinya terhadap model pembelajaran tersebut. Artikel ini mengkaji tentang persepsi mahasiswa terhadap skenario pembelajaran menggunakan model pembelajaran problem based learning. Penelitian ini menggunakan metode deskriptif kuantitatif. Persepsi mahasiswa dilihat dari tiga aspek yaitu kesiapan, minat, dan profil pembelajaran. Persepsi mahasiswa tentang kepercayaan diri dan partisipasi aktif mahasiswa bukan dipengaruhi oleh model pembelajaran yang digunakan tetapi lebih dipengaruhi oleh materi yang dipelajari. Persepsi minat mahasiswa terhadap pelaksanaan PBL cukup baik dan persepsi mahasiswa terhadap profil pembelajaran PBL sangat baik. Persepsi mahasiswa terhadap profil pembelajaran sudah sangat baik, hanya saja pada tahapan orientasi masalah dan evaluasi terhadap proses penyelesaian masalah perlu ditingkatkan karena tahapan ini merupakan salah satu tahapan yang penting dalam model pembelajaran problem based learning.

Problem-based learning model is one of the learning models used in the $2 \mathrm{I}^{\text {st }}$-century learning process. The implementation of the learning process can be seen from the readiness of the teacher and students. Readiness can be seen from their perceptions of the learning model. This article examines the students' perception of learning scenarios using problem-based learning. This research uses the quantitative descriptive method. Student perceptions showed three aspects: readiness, interest, and learning profile. Student perceptions about self-confidence and participation not only influenced by using the model but also influenced by the content of the material. The perception of student interest in PBL implementation is good and students' perception of the PBL learning profile is very good. Student perceptions of the learning profile have been very good, only at the stage of problem orientation and evaluation of the problemsolving process needs to be improved.

Kata kunci: persepsi, skenario pembelajaran, problem based learning

\section{Pendahuluan}

Perguruan tinggi merupakan lembaga yang mencetak generasi yang akan terjun di dunia nyata. Kehidupan di abad ke-2I ini menuntut manusia untuk memiliki berbagai keterampilan. Keterampilan pada abad ke-2I masih relevan dengan empat pilar kehidupan yang mencakup learning to know, learning to do, learning to be dan learning to live together. Oleh karena itu, pendidikan tinggi diharapkan dapat mempersiapkan mahasiswa untuk menguasai berbagai keterampilan tersebut agar menjadi pribadi yang sukses dalam hidup.

Empat pilar kehidupan tersebut masing-masing mengandung keterampilan khusus yang perlu diberdayakan dalam kegiatan pembelajaran, seperti keterampilan berpikir kritis, metakognisi, pemecahan masalah, keterampilan berkomunikasi, inovasi dan kreasi, dan berbagai keterampilan lainnya. Keterampilan abad ke2I dapat dicapai dengan meningkatkan kualitas pembelajaran. Pembelajaran di perguruan tinggi diharapkan dapat membantu mahasiswa meningkatkan partisipasi, motivasi, komunikasi, kreativitas, dan inovasi 
dalam belajar. Model pembelajaran problem based learning merupakan salah satu model pembelajaran yang dapat digunakan untuk meningkatkan keterampilan abad ke-2I. Yusof, K. M. et al menyebutkan bahwa problem based learning merupakan salah satu metode pengajaran dan pembelajaran yang efektif untuk menghadapi tantangan abad ke-2I[I].

Problem based learning diterapkan pada mata kuliah Ilmu Pengetahuan Bumi dan Antariksa (IPBA) pada mahasiswa semester II program studi pendidikan IPA Universitas Tidar. Untuk mengaplikasikan model pembelajaran problem based learning pada mata kuliah yang lain peneliti mengkaji persepsi mahasiswa terhadap implementasi problem based learning.

\section{Kajian Pustaka}

Problem-Based Learning (PBL) adalah pendekatan pembelajaran induktif yang menggunakan masalah realistis sebagai titik awal pembelajaran. Tidak seperti dalam pendidikan kedokteran, yang lebih mudah beradaptasi dengan PBL, menerapkan PBL dalam mata kuliah teori seperti Ilmu Pengetahuan Bumi dan Antariksa (IPBA) merupakan suatu tantangan. Zhang, $\mathrm{Y}$ et al menyebutkan bahwa penerapan model pembelajaran PBL dalam mata kuliah pengantar sarjana dapat meningkatkan tingkat keunggulan ujian dan nilai dalam sistem pendidikan medis Cina [2]. Ini lebih efektif bila diterapkan pada program laboratorium daripada kursus berbasis teori. Mata kuliah IPBA merupakan salah satu mata kuliah teori yang mengkaji tentang fenomenafenomena yang ada di bumi dan antariksa.

Pembelajaran berbasis masalah (PBL) disebut-sebut sebagai salah satu metode pengajaran dan pembelajaran yang efektif untuk menghadapi tantangan abad ke-2I[I]. Pembelajaran problem based learning ini diawali dengan pemberian masalah pada mata kuliah ilmu pengetahuan bumi dan antariksa. Permasalahan yang diberikan terkait dengan fenomena-fenomena alam yang terjadi di lingkungan sekitar. Berawal dari permasalahan tersebut, mahasiswa secara aktif mengontruksi permasalahan dan mencari solusinya dengan mengkaji teori-teori terkait ilmu pengetahuan bumi dan antariksa. Proses pembelajaran mengarahkan mahasiswa untuk bekerja secara individu dan kelompok, yang pada akhirnya solusi dari permasalahan dipresentasikan sebagai bahan diskusi.

Model PBL dibandingkan dengan kurikulum teknik tradisional dapat menginspirasi tingkat keterlibatan yang lebih tinggi dalam kegiatan belajar yang diharapkan pada pemahaman yang lebih tinggi[3]. Kelemahan yang mungkin adalah risiko kesenjangan di bidang pengetahuan tertentu. Oleh karena itu, penting bagi mahasiswa dalam pembelajaran PBL menjadi pembelajar seumur hidup yang telah belajar mengambil tanggung jawab untuk proses belajar mereka sendiri.

Beberapa penelitian pembelajaran dengan problem based learning dapat meningkatkan kemampuan akademik [4], [5], [6], dan [7]. Problem based learning mendukung pembelajaran aktif, memberikan keterampilan bekerjasama dalam kelompok, meningkatkan keterampilan pemecahan masalah, meningkatkan literasi sains, meningkatkan keterampilan proses sains, meningkatkan pengetahuan, meningkatkan kemampuan belajar mandiri, meningkatkan keterampilan berpikir kritis, dan membangun keterampilan berkomunikasi [8].

Persepsi merupakan sudut pandang seseorang dalam menilai sesuatu. Kajian pada artikel ini melihat persepsi mahasiswa semester II Program Studi Pendidikan IPA Universitas Tidar terhadap pelaksanaan pembelajaran pada mata kuliah IPBA dengan model pembelajaran PBL. Persepsi mahasiswa didasarkan pada tiga aspek yaitu kesiapan, minat, dan profil pembelajaran [9]. Indikator aspek kesiapan meliputi kepercayaan diri, berpartisipasi aktif, kesesuaian dengan nilai pembelajaran Sains, kesesuaian dengan tujuan kinerja, dan kesesuaian dengan tujuan pencapaian. Indikator aspek minat meliputi memperhatikan, ketertarikan, dan kemauan belajar. Indikatornya meliputi orientasi masalah, mengorganisasikan, membimbing penyelidikan, menyajikan hasil, dan menganalisis dan mengevaluasi proses pemecahan masalah

\section{Metode Penelitian}

Penelitian ini menggunakan metode penelitian deskriptif kuantitatif. Sampel dalam penelitian ini adalah mahasiswa Pendidikan IPA Universitas Tidar tahun ajaran 2017/2018 yang berjumlah 66 orang. Instrumen dalam penelitian ini adalah lembar angket persepsi mahasiswa yang terdiri dari 39 item penilaian. Aspek penilaian persepsi terdiri dari tiga aspek yaitu kesiapan mahasiswa, minat, dan profil pembelajaran menggunakan model pembelajaran problem based learning.

Hasil penilaian angket persepsi mahasiswa terhadap kegiatan pembelajaran dianalisis dalam bentuk persentase menggunakan rumus berikut.

$$
P=\frac{\sum X_{I}}{n} \times 100 \%
$$

Keterangan:

$$
\begin{array}{ll}
\mathrm{p} & : \text { persentase } \\
\Sigma X_{I} & : \text { jumlah jawaban mahasiswa yang diperoleh } \\
\mathrm{N} & : \text { jumlah skor maksimal }
\end{array}
$$




\section{Hasil Penelitian dan Pembahasan}

Hasil isian angket dianalisis pada setiap indikator dan dipersentase untuk melihat perbandingannya pada nilai maksimal. Data persentase angket persepsi mahasiswa terhadap pelaksanaan pembelajaran dengan model pembelajaran PBL disajikan dalam tabel I.

Tabel I. Persentase Skor Persepsi Mahasiswa terhadap Pelaksanaan Model PBL

\begin{tabular}{clc}
\hline No. & \multicolumn{1}{c}{ Indikator } & Persentase \\
\hline I & Kesiapan & \\
& Kepercayaan Diri & $60 \%$ \\
& Berpartisipasi Aktif & $72 \%$ \\
& Kesesuaian dengan Nilai Pembelajaran & $96 \%$ \\
& Sains & \\
& Kesesuaian dengan Tujuan Kinerja & $96 \%$ \\
& Kesesuaian dengan Tujuan Pencapaian & $98 \%$ \\
\hline 2 & Minat & \\
& Memperhatikan & $55 \%$ \\
& Ketertarikan & $57 \%$ \\
& Kemauan Belajar & $55 \%$ \\
\hline 3 & Profil Pembelajaran & $66 \%$ \\
& Orientasi Masalah & $83 \%$ \\
& Mengorganisasikan & $93 \%$ \\
Membimbing Penyelidikan & $87 \%$ \\
Menyajikan Hasil & $70 \%$ \\
Menganalisis dan Mengevaluasi Proses & \\
Pemecahan Masalah &
\end{tabular}

Pada aspek kesiapan, penilaian tertinggi kesesuaian dengan tujuan pencapaian yang meliputi kemampuan riset, kemampuan berpikir kritis, kreatif dan inovatif dengan persentase $98 \%$. Dalam persepsi mahasiswa tentang tujuan pencapaian menunjukkan kemampuan riset mereka mulai digali, sebagian lainnya menilai bahwa kemampuan riset dalam model pembelajaran ini belum dilakukan secara mendalam. Kemampuan berpikir kritis, kreatif dan inovatif dilatih saat mahasiswa menyelesaikan permasalahan dan pada saat mempresentasikan hasil kajiannya terhadap permasalahan. Penilaian terendah pada aspek kesiapan adalah pada indikator kepercayaan diri, yaitu 60\%. Keyakinan mahasiswa dalam memahami materi karena adanya video yang ditampilkan untuk menjelaskan fenomena-fenomena yang dikaji dan fenomena tersebut melekat dalam kehidupan sehari-hari mereka. Akan tetapi keyakinan mahasiswa untuk menyelesaikan tahapan pembelajaran yang sulit masih rendah karena mereka merasa masih membutuhkan penjelasan yang runtut dari dosen. Partisipasi aktif diartikan oleh semua mahasiswa dengan cara terlibat secara lisan dalam diskusi di kelas, meskipun sebenarnya partisipasi aktif dapat dilakukan dengan aktivitas mental dan emosional. Kepercayaan diri dan partisipasi aktif mahasiswa bukan karena model pembelajaran yang digunakan, tetapi bergantung pada materi yang diajarkan. Menurut Thomas \& Schwenz PBL dapat mendukung pembelajaran aktif, tetapi bukan partisipasi aktif dari mahasiswa. Partisipasi aktif dari mahasiswa salah satunya bergantung pada mood mahasiswa terhadap materi yang sedang dipelajari.

Penilaian pada aspek minat untuk indikator memperhatikan, ketertarikan, dan kemauan belajar masing-masing 55\%, 57\%, dan 55\%. Pada indikator memperhatikan, sebagian berpendapat pada saat tidak memperhatikan bukan karena materi atau tahapan pembelajaran yang membosankan tetapi terkadang pihak yang mempresentasikan hasil yang membosankan sehingga menjadi kurang fokus.Pada indikator ketertarikan, 70 persen mahasiswa merasa tidak senang dengan tugas lanjutan karena tugas yang harus dikerjakan oleh mahasiswa sangat banyak. Akan tetapi pada saat tugas tersebut berupa praktek membuat model, mahasiswa merasa antusias. Indikator kemauan belajar bernilai rendah pada pernyataan mahasiswa segera mengerjakan tugas. Tugas yang diberikan oleh dosen dikerjakan sesuai dengan waktu luang yang dimiliki oleh mahasiswa. Persepsi minat mahasiswa terhadap pelaksanaan pembelajaran PBL cukup baik, tetapi tugas lanjutan yang diberikan dalam mata kuliah IPBA mengurangi minat mahasiswa terhadap pelaksanaan perkuliahan.

Pada aspek profil pembelajaran, persepsi mahasiswa dilihat pada setiap tahapan skenario pembelajaran problem based learning (PBL). Orientasi masalah dinilai $66 \%$, sebagian mahasiswa tidak membaca rencana pelaksanaan pembelajaran (RPS) terlebih dahulu sehingga tujuan permasalahan mereka ketahui ketika awal masuk setiap pertemuan. Indikator mengorganisasikan masalah bernilai $83 \%$ karena dalam mengorganisasikan masalah diikuti dengan konsultasi dalam upaya penyelesaian masalah. Pada indikator pembimbingan penyelidikan, 93\% mahasiswa memberikan penilaian bahwa proses pembimbingan penyelidikan menambah informasi dan membantu mahasiswa agar tidak terjadi kesalahan dalam upaya penyelesaian masalah. Pada tahapan menyajikan hasil, persepsi mahasiswa $87 \%$ aktif dalam menyelesaikan dan proses penyajian hasil dapat meningkatkan kemampuan berkomunikasi, tetapi terkadang dalam menyajikan kurang menarik sehingga ada beberapa mahasiswa yang tidak memperhatikan. Pada tahapan menganalisis dan mengevaluasi proses pemecahan masalah persentasenya $70 \%$. Hal yang bernilai paling kecil yaitu pada menyampaikan pertanyaan atau argumen. Sebagian berpendapat bahwa mereka tidak selalu mendapat kesempatan untuk menyampaikan pertanyaan. Secara umum persepsi mahasiswa terhadap profil pembelajaran PBL sangat baik, hanya terletak pada orientasi masalah dan tahapan evaluasi pada proses pemecahan masalah. 


\section{Kesimpulan}

Persepsi mahasiswa terhadap pelaksanaan pembelajaran problem based learning didasarkan pada tiga aspek yaitu kesiapan, minat, dan profil pembelajaran. Aspek kesiapan berada pada kategori cukup baik pada indikator kepercayaan diri dan partisipasi aktif. Indikator kesesuaian dengan nilai pembelajaran sains, kesesuaian dengan tujuan kinerja, dan kesesuaian dengan tujuan pencapaian berada pada kategori sangat baik. Persepsi mahasiswa pada aspek minat sudah cukup baik, tetapi tugas tambahan yang diberikan mengurangi minat mahasiswa terhadap pelaksanaan PBL. Persepsi mahasiswa terhadap profil pembelajaran sudah sangat baik, hanya saja pada tahapan orientasi masalah dan evaluasi terhadap proses penyelesaian masalah perlu ditingkatkan.

\section{Ucapan Terimakasih}

Ucapan terimakasih ditujukan kepada Allah swt yang memberikan rahmat serta hidayahnya sehingga penelitian ini dapat diselesaikan tepat waktu. Ucapan terima kasih juga disampaikan kepada DIPA Universitas Tidar (UNTIDAR) tahun 2018 yang sudah memberikan dana untuk mendukung penelitian ini.

\section{Kepustakaan}

[I] K. M. Yusof, S. A. H. Syed Hasan, M. Z. Jamaludin, N. F. Harun, Cooperative Problem-based Learning (CPBL): Framework for Integrating Cooperative Learning and Problembased Learning, Social and Behavioral Sciences, vol. 56, 2012, pp. 223-232. Doi: http://doi.org/I0.1016/j.sbspro.2012.09.649.

[2] Y. Zhang, L. Zhou, X. Liu, L. Liu, Y. Wu, Z. Zhao, D. Yi, The Effectiveness of the Problem-Based Learning Teaching Model for Use in Introductory Chinese Undergraduate Medical Courses: A Systematic Review and Meta-Analysis, PLoS ONE, vol.IO no.3, 2015, e0I20884. Doi: http://doi.org/I0.I37I/journal.pone.0I20884

[3] E. De Graff \& A. Kolmos, Characteristics of Problem-Based Learning. International Journal of Enginering Education, vol. I9, no. 5, 2003, pp 657-662.

[4] A. Gurses, C. Dogar, E. Geyik, Teaching of The Concept of Enthalpy using Problem Based Learning Approach. ProcediaSocial and Behavioral Sciences, vol. 197, 2015, pp. 2390-2394. Doi: http://doi.org/I0.I0I6/j.sbspro.2015.07.298.

[5] S. M. M. Loyens, S. H. Jones, J. Mikkers, T. van Gog, Problembased Learning as A Facilitator of Conceptual Change. Learning and Instruction, vol. 38, 2015, pp. 34-42. Doi: http://dx.doi.org/I0.1016/j.learninstruc.2015.03.002.

[6] R. Phungsuk, C. Virijavejakul, T. Ratanaolarn, Development of A Problem-based Learning Model Via A Virtual Learning Environment, Kasetsart Journal of Social Sciences, vol. 38, 2017, pp. 297-306. Doi: http://dx.doi.org/I0.I0I6/j.kjss.20I7.0I.00I

[7] E. H. J. Yew, K. Goh, Problem-Based Learning: An Overview of its Process and Impact on Learning, Health Professions Education, vol. 2, 2016, pp. 75-79. Doi: http://dx.doi.org/I0/I0I6/j.hpe.2016.01.004
[8] P. L. Thomas \& R. W. Schwenz, College Physical Chemistry Students' Conceptions of Equilibrium and Fundamental Thermodynamics, Journal Research in Science Teaching, vol. 35 no. I0, I998, pp. II5I - II60.

[9] C. Coubergs, K. Struyven, G. Vanhournout, N. Engels, Measuring Teachers' Perceptions about Differentiated Instruction: The DI-Quest Instrument and Model, Studies in Educational Evaluation, vol. 53, 2017, pp. 4I-54. Doi: http://dx.doi.org/I0.1016/j.stueduc.2017.02.004

\section{Appendix}

Tabel 2. Persentase Angket Persepsi Mahasiswa terhadap Pelaksanaan PBL pada setiap Pernyataan

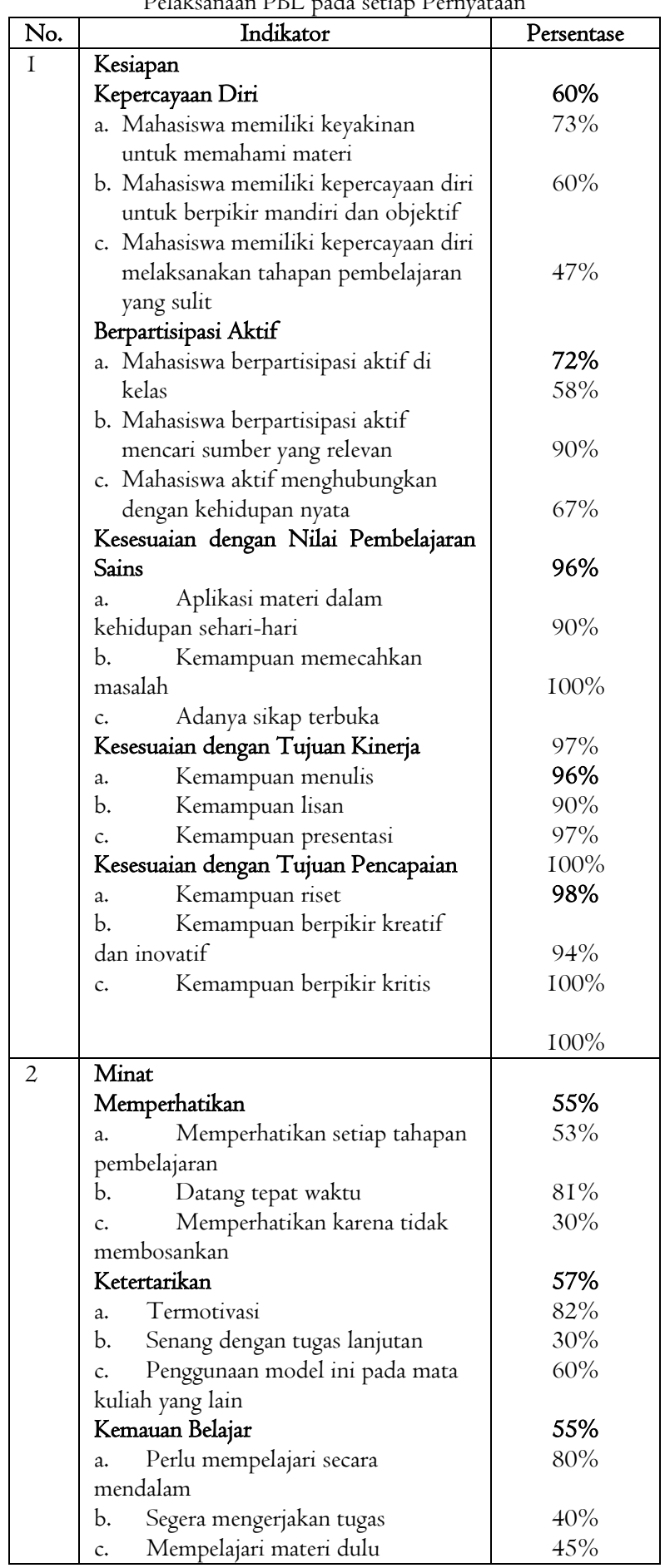




\begin{tabular}{|c|c|c|}
\hline $\begin{array}{l}\text { No. } \\
3\end{array}$ & Indikator & Persentase \\
\hline & Profil Pembelajaran & \\
\hline & Orientasi Masalah & $66 \%$ \\
\hline & a. Mahasiswa mengetahui tujuan & $60 \%$ \\
\hline & perkuliahan & \\
\hline & b. Mahasiswa mengetahui & $40 \%$ \\
\hline & konsep/materi yag dipelajari & \\
\hline & Permasalahan menjadikan & $97 \%$ \\
\hline & berpikir kritis & \\
\hline & Mengorganisasikan & $83 \%$ \\
\hline & a. Informasi yang detail membantu & $90 \%$ \\
\hline & penyelidikan & \\
\hline & $\begin{array}{l}\text { b. Permasalahan butuh berpikir } \\
\text { tingkat tinggi untuk menyelesaikan }\end{array}$ & $80 \%$ \\
\hline & $\begin{array}{l}\text { c. Mengorganisasi petunjuk untuk } \\
\text { menvelesaikan masalah }\end{array}$ & \\
\hline & Membimbing Penyelidikan & $80 \%$ \\
\hline & Mendapat bimbingan dosen & \\
\hline & Proses penyelidikan/mencari & $93 \%$ \\
\hline & informasi & $100 \%$ \\
\hline & c. Proses pembimbingan & $80 \%$ \\
\hline & menambah informasi & ४०० \\
\hline & Menyajikan Hasil & $100 \%$ \\
\hline & Aktif menyelesaikan masalah & \\
\hline & Meningkatkan kemampuan & $87 \%$ \\
\hline & berkomunikasi & $100 \%$ \\
\hline & Memperhatikan kelompok & $100 \%$ \\
\hline & lain presentasi & \\
\hline & Menganalisis dan Mengevaluasi Proses & $60 \%$ \\
\hline & Pemecahan Masalah & \\
\hline & $\begin{array}{l}\text { a. } \\
\text { masalah }\end{array}$ & $70 \%$ \\
\hline & Evaluasi pemecahan masalah & $100 \%$ \\
\hline & c. Menyampaikan Pertanyaan & $80 \%$ \\
\hline & atau argumen & $30 \%$ \\
\hline
\end{tabular}

